\title{
Power Conditioning Issue
}

National Cancer Institute

\section{Source}

National Cancer Institute. Power Conditioning Issue. NCI Thesaurus. Code C62868.

Problem associated with a momentary overpower/over voltage from the utility and electrical systems of user facilities; or inadequate power conditioning such as the presence of fluctuation, surges, spikes, dropouts, noise and other such undesirable transients. 